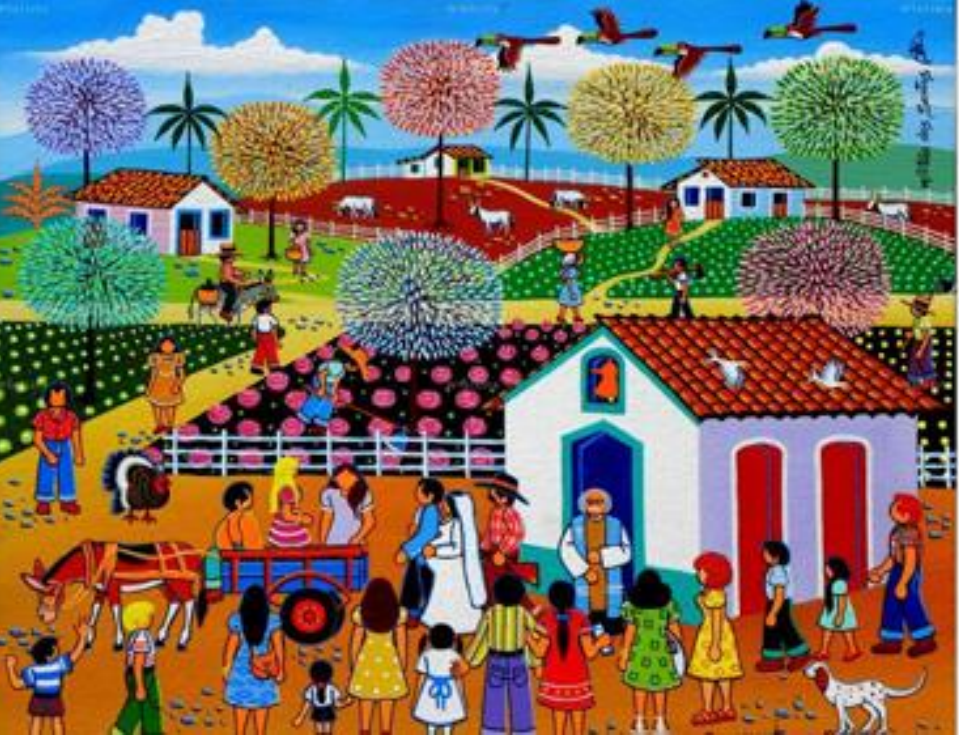

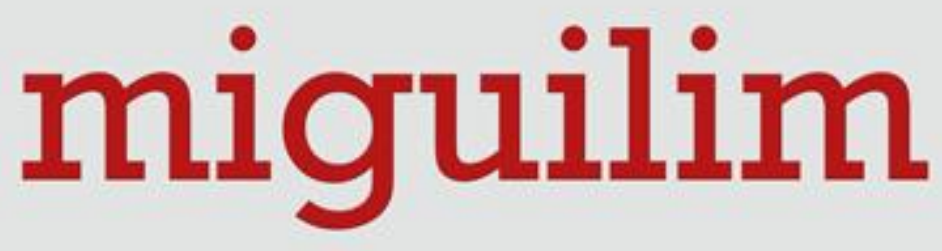

revista eletrônica do netlli

volume 8, número 1, jan.-abr. 2019

\title{
OS MARCADORES CONVERSACIONAIS DE MODALIDADE DEÔNTICA NAS ENTREVISTAS DO PAPA FRANCISCO
}

\author{
THE CONVERSATIONAL MARKERS OF THE DEONTIC \\ MODALITY IN THE INTERVIEWS OF POPE FRANCISCO
}

\author{
André Silva OLIVEIRA \\ Universidade Federal do Ceará, Brasil
}

\begin{abstract}
RESUMO | INDEXAÇÃO | TEXTO | REFERÊNCIAS | CITAR ESTE ARTIGO | O AUTOR RECEBIDO EM 02/02/2019 • APROVADO EM 12/04/2019
\end{abstract}

\section{Resumo}

Este estudo apresenta a descrição e análise dos marcadores conversacionais de modalidade deôntica encontrados em entrevistas concedidas pelo Papa Francisco em língua espanhola e realizadas entre os anos de 2014 e 2017. O corpus compõe-se de seis entrevistas de divulgação on-line e escolhidas, particularmente, apenas com base na quantidade mínima de 2.000 palavras para que pudéssemos encontrar o maior número possível de marcadores conversacionais, sem que nos detivéssemos em questões mais restritivas, como entrevistas, especificamente, de cunho político, religioso, econômico, social, etc. Com base em uma análise qualitativa dos marcadores conversacionais de modalidade deôntica, os resultados mostram que eles são empregados pelo falante, no caso desta pesquisa, o Papa Francisco, para manifestar as suas atitudes no que diz respeito não apenas à expressão de suas vontades e afetos, como já é previsto nos trabalhos de Zorraquino e Portolés (1999), Agüero (2016), Ramírez (2016), Taibo-Cao (2016) e Mafud e Carmona (2018), mas também para fazer uma 
apreciação das suas obrigações ao admiti-las como certas a partir do que se infere do fragmento do discurso ao qual remetem.

\section{Abstract}

This study presents the description and analysis of the conversational markers of deontic modality found in interviews given by Pope Francisco in Spanish and carried out between 2014 and 2017. The corpus is composed of six on-line and chosen publicity interviews, particularly, only based on the minimum quantity of 2,000 words so that we could find as many conversational markers as possible, without dwelling on more restrictive questions, such as interviews, specifically of a political, religious, economic or social nature. Based on a qualitative analysis of the conversational markers of deontic mode, the results show that they are employed by the speaker, in the case of this research, Pope Francis, to express his attitudes regarding not only the expression of his wills and affections (2016), Ramírez (2016), Taibo-Cao (2016) and Mafud and Carmona (2018), but also to make an appreciation of his obligations to the admitted they are certain from what is inferred from the fragment of discourse to which they refer.

\section{Entradas para indexação}

PALAVRAS-CHAVE: Língua espanhola. Discurso oral. Discursividade. Deonticidade. KEYWORDS: Spanish language. Oral speech. Discursive. Deonticity.

\section{Texto integral}

Descrever e analisar os diferentes tipos de conversação, seja por meio de conversações informais, como amigos conversando em um bar, discutindo sobre política, futebol, etc., ou por meio de conversações formais, como uma consulta entre médico e paciente ou uma entrevista de emprego, é um viés indispensável aos estudos linguísticos, haja vista que essa modalidade, a conversação, é uma das práticas sociais mais frequentes no cotidiano das pessoas. Nesse sentido, pretendemos realizar um estudo acerca dos conceitos e das características inerentes aos marcadores conversacionais, concretamente, os de modalidade deôntica, já que o emprego deles está, inevitavelmente, presente nos mais variados tipos de conversações, entre elas, as entrevistas concedidas pelo Papa Francisco.

Objetivamos, dessa forma, descrever e analisar, qualitativamente, as funções preenchidas pelos marcadores conversacionais de modalidade deôntica em seis entrevistas concedidas pelo Santo Padre em língua espanhola, realizadas entre os anos de 2014 e 2017 e que compuseram o corpus desta pesquisa. Primeiramente, faremos uma abordagem dos pressupostos teóricos sobre marcadores conversacionais apresentados por Zorraquino e Portolés (1999). Em seguida, discorreremos acerca dos marcadores conversacionais de modalidade deôntica que, segundo Agüero (2016), Ramírez (2016), Taibo-Cao (2016) e Mafud e Carmona (2018), são unidades linguísticas que expressam as atitudes do falante 
acerca das suas vontades e de seus afetos, confirmando-os ou recusando-os em virtude daquilo que lhe é proposto durante a interação.

$\mathrm{Na}$ sequência, apresentamos a descrição e análise dos marcadores conversacionais de modalidade deôntica encontrados nas entrevistas do Papa Francisco. Em relação ao gênero entrevista, Dolz e Schneuwly (2013) definem-no como um gênero jornalístico em que a pessoa entrevistada, geralmente, trata-se de um expert em um dado assunto, e a quem o entrevistador formula uma série de perguntas no intuito de comunicar informações e pontos de vista do entrevistado acerca da temática estipulada previamente e que irá guiar a entrevista. A escolha do gênero entrevista, portanto, deu-se em virtude da possibilidade de encontrarmos uma quantidade significativa de marcadores conversacionais de modalidade deôntica. Finalmente, apresentamos as considerações finais acerca da análise empreendida acerca dos marcadores conversacionais de modalidade deôntica.

\section{Os marcadores conversacionais na perspectiva de Zorraquino e Portolés (1999)}

No que diz respeito à definição dos marcadores conversacionais, existe uma grande quantidade de teorias, conceitos e denominações acerca deles, ainda que a atenção que se tenha dado a eles seja relativamente nova, como pontua Carbonero e Marrero (2010). No entanto, ainda segundo as autoras, uma das classificações mais empregadas para a descrição e análise dos marcadores conversacionais é a de Zorraquino e Portolés (1999), em que se podem verificar cinco funções principais: são estruturadores de informação, agindo como conectores e reformuladores de informação, além de atuarem como operadores argumentativos e, obviamente, como marcadores conversacionais. Estas funções operacionais básicas dos marcadores conversacionais podem ser aplicadas para os estudos voltados para as conversas orais, tais como telefonemas, aulas, entrevistas, etc. De acordo com os autores, os marcadores conversacionais são, basicamente, definidos como unidades invariáveis que não exercem qualquer tipo de função sintática na oração, sendo, portanto, elementos marginais que possuem apenas a função de guiar as inferências realizadas na comunicação a partir de suas propriedades morfossintáticas, semânticas e pragmáticas.

Conforme Zorraquino e Portolés (1999), em quase todas as gramáticas de língua espanhola, as partículas consideradas invariáveis, como os advérbios, as preposições, as conjunções, as interjeições e outros elementos gramaticalizados podem desempenhar funções discursivas dependendo do contexto em que são utilizados pelos participantes da interação. Entretanto, ainda segundo os autores, é necessário destacar que os marcadores conversacionais não são tão fáceis de sistematizar, já que não se tratam de uma classe uniforme de palavras, ou seja, não é possível fazer uma relação estritamente precisa entre o conceito de marcador do discurso e uma categoria gramatical determinada. Ainda assim, segundo os autores, é possível que se possa fazer uma descrição sistemática dos marcadores conversacionais a partir de um conjunto de elementos que compartilham 
propriedades discursivas, dos quais os autores destacam o fato deles: (i) pertencerem a categorias tradicionais de advérbios, locuções adverbiais e certas interjeições; e (ii) possuírem características semânticas, tais como a forma de significar e de configurar o significado dentro do contexto situacional da interação.

Além de possuírem essas propriedades discursivas, Zorraquino e Portolés (1999) ainda delimitam os marcadores conversacionais nos níveis prosódicos, morfológicos, sintáticos e semânticos. Prosodicamente, os marcadores conversacionais são limitados como parêntesis pela entonação, indicado por uma pausa na comunicação oral e entre aspas na comunicação escrita. Morfologicamente, são unidades linguísticas que não variam, enquanto, sintaticamente, são unidades não integradas à oração, podendo este grau de autonomia variar conforme o tipo de marcador discursivo empregado, não apresentando, também, uma posição fixa, uma coordenação entre si e a admissão de qualquer tipo de negação. Semanticamente, os marcadores conversacionais são elementos que não apresentam um conteúdo referencial ou denotativo, restringindo-se apenas a guiar o processamento discursivo, dando-lhe um significado no contexto em que é empregado. Com base nessas propriedades compartilhadas pelos marcadores conversacionais, os autores subdividem os marcadores conversacionais em: estruturadores de informação, conectores, reformuladores, operadores argumentativos e marcadores conversacionais.

Os estruturadores de informação agem na estruturação da informação veiculada na interação, funcionando como "comentadores" de determinados assuntos. Eles se dividem em: (i) comentadores, que apresentam um novo comentário, como no exemplo: He dicho que vemos desde la memoria; pues bien, también percibimos desde el linguaje [Eu disse que vemos desde a memória; pois bem, também percebemos desde a linguagem] (ZORRAQUINO; PORTOLÉS, 1999, p. 4085); (ii) ordenadores, que agrupam vários membros discursivos como partes de um único comentário, como no exemplo: Sí, tiene un nivel un poco más alto, por un lado y luego por otro lado pues... con dos idiomas perfectamente aprendidos ¿no? [Sim, tem um nível um pouco mais alto, por um lado, e depois por outro lado, pois... com dois idiomas perfeitamente aprendidos, não?] [ZORRAQUINO; PORTOLÉS, 1999, p. 4086); e (iii) digressores, que sinalizam os elementos do discurso como um comentário lateral em relação à planificação daquilo que foi veiculado anteriormente, como no exemplo: iY no digamos nada de Marcelino! ¡Está tan enamorado de ella!... Por cierto me choca mucho que no esté ya en casa, ¿verdad? [E não digamos nada de Marcelino! Está tão apaixonado por ela!... Por certo, me choca muito que não esteja em casa, não é mesmo?] (ZORRAQUINO; PORTOLÉS, 1999, p. 4091);

Os conectores veiculam semântica e pragmaticamente um elemento do discurso com outro elemento anterior, proporcionando uma série de instruções argumentativas que guiam as inferências do conjunto dos elementos relacionados. Eles se dividem em: (i) aditivos, que se referem a elementos que unem a um elemento discursivo anterior a outro com a mesma orientação argumentativa, permitindo, pois, a dedução de conclusões que seriam dificilmente deduzíeis se esses elementos permanecessem independentes, como no exemplo: Debemos llevar al niño al hospital. Tiene mucha fiebre e, incluso, ha comenzado a delirar [Devemos 
levar à criança ao hospital. Tem muita febre e, inclusive, começou a delirar] (ZORRAQUINO; PORTOLÉS, 1999, p. 4097); (ii) consecutivos, que apresentam o elemento do discurso, em que se encontram, como uma consequência de um elemento anterior, introduzindo um efeito dedutivo da informação anterior, ao representar a causa, como no exemplo: Efectivamente, el arte nos transmite verdad $y$, por tanto el arte es conocimiento [Efetivamente, a arte nos transmite verdade, e, portanto, a arte é conhecimento] (ZORRAQUINO; PORTOLÉS, 1999, p. 4101); e (iii) contra-argumentativos, que veiculam dois elementos de tal forma, que o segundo se apresenta como um supressor de uma conclusão que se pode obter do primeiro, como no exemplo: No le gustan las bebidas alcohólicas. Antes bien, las aborrece [Eu não gosto de bebidas alcoólicas. Pelo contrário, elas me aborrecem] (ZORRAQUINO; PORTOLÉS, 1999, p. 4109).

Os reformuladores são marcadores que apresentam o elemento do discurso que introduzem como uma nova formulação de um elemento anterior, em que o falante reformula o que já havia dito, empregando um reformulador para apresentar o elemento do discurso que o segue como uma melhor expressão daquilo que foi dito anteriormente. Eles se dividem em: (i) explicativos, que apresentam o segundo elemento do discurso como uma explicação do elemento anterior, como no exemplo: No tengo el recibo del banco. $\underline{O}$ sea no lo he encontrado [Não tenho o recibo do banco. Ou seja, não o encontrei] (ZORRAQUINO; PORTOLÉS, 1999, p. 4123); (ii) retificativos, que corrigem um membro anterior, como no exemplo: El no tener papá, o, mejor dicho que mi papá estuviera en el cielo, no era algo que me atormentaba [0 fato de não ter mais meu pai, ou, melhor dizendo, que meu pai estivesse no céu, não era algo que me atormentava] (ZORRAQUINO; PORTOLÉS, 1999, p. 4126); (iii) reformuladores de distanciamento, que mostram a nova formulação como aquela que condicionará a continuidade do discurso, ao mesmo tempo em que priva a relevância do elemento discurso que a precede, como no exemplo: Nos ha dado mucha pena que se llevaran el quiosco, porque es el pan nuestro de cada día. De todas formas, pronto volveremos a abrir. Aunque no sabemos donde [Sentimos muito por levar o quiosque, porque é o nosso pão de cada dia. De qualquer forma, vamos reabrir em breve. Embora não saibamos onde] (ZORRAQUINO; PORTOLÉS, 1999, p. 4129); e (iv) recapitulativos, que introduzem um elemento do discurso com uma recapitulação ou uma conclusão a partir de outro elemento precedente, como no exemplo: Acepte usted que el ser es tiempo: pasar, declinar, madurar, envejecer. En suma: caducidade [Aceite que o ser é tempo: passar, declinar, amadurecer, envelhecer. Em suma: vencimento] (ZORRAQUINO; PORTOLÉS, 1999, p. 4133).

Os operadores argumentativos condicionam, por meio do seu significado, as possibilidades argumentativas dos elementos do discurso no qual estão incluídos, mas sem que façam qualquer tipo de relação com os elementos citados anteriormente. Eles se dividem em: (i) reforço argumentativo, que agem como argumento de reforço em relação ao elemento do discurso no qual se encontram, como no exemplo: $Y$ en esta [estancia] cada día se sentía mejor, a punto que siguió postergando su retorno a Lima donde, en realidad, no tenía nada que hacer [E nessa estância ele se sentia melhor a cada dia, a ponto de continuar adiando seu retorno à Lima, onde, na realidade, ele não tinha nada para fazer] (ZORRAQUINO; 
PORTOLÉS, 1999, p. 4141); e (ii) concreção, que agem também como argumento de reforço em relação ao elemento do discurso em que se encontram, mas apresentando-o como um tipo de exemplificação, como no exemplo: La vida te obsequia, a veces, con deslumbrantes despertares: un día de lluvia, por ejemplo [A vida te dá, às vezes, despertares deslumbrantes: um dia chuvoso, por exemplo] (ZORRAQUINO; PORTOLÉS, 1999, p. 4142).

Os marcadores conversacionais referem-se à função informativa, que é orientada para a mensagem, e à função interativa, que, por sua vez, é orientada para o ouvinte, favorecendo as mudanças de tema na conversação e o uso de expressões que indicam que o falante recebeu e processou a mensagem. Eles se dividem em marcadores de: (i) enfocadores de alteridade, que são unidades que coincidem com aquilo a que se veiculam, em sua origem, fundamentalmente, ao ouvinte, sendo em alguns casos, a ambos os participantes da interação, como no exemplo: Hombre aquí hay una farmacia de guardia [Homem, aqui tem uma farmácia 24 horas] (ZORRAQUINO; PORTOLÉS, 1999, p. 4173); (ii) metadiscursivos conversacionais, que integram os procedimentos que utilizam os participantes da interação para a construção da conversação, representam, portanto, os elementos de esforço do qual os participantes se utilizam para formular e organizar o seu discurso, como no exemplo: A: ¿Cuántos años hace que veraneas en Lecumberri? B: Sí. Vinimos aquí en el 56... [A: Há quanto tempo vocês passam o verão em Lecumberri? B: Sim, Viemos aqui desde 56...] (ZORRAQUINO; PORTOLÉS, 1999, p. 4193); (iii) modalidade epistêmica, que são utilizados em enunciados declarativos, constituindo-se em afirmações que refletem o enfoque do falante em relação à mensagem que o marcador empregado introduz, como no exemplo: Juan, claro, vendrá el lunes [Juan, claro, virá na segunda] (ZORRAQUINO; PORTOLÉS, 1999, p. 4146); e (iv) modalidade deôntica, que refletem as atitudes do falante no que diz respeito à expressão de seus desejos e de suas vontades, indicando, pois, se o falante aceita ou não aceita aquilo que se infere na parte do discurso ao qual se refere, como no exemplo: A: ¿Vamos a los toros? B: Bien. Bueno. Vale [A: Vamos ver as touradas? B: Bem. Tá bom. Ok] (ZORRAQUINO; PORTOLÉS, 1999, p. 4169).

Como vimos os marcadores conversacionais propostos por Zorraquino e Portolés (1999) dividem-se com base nas funções que eles veiculam no encadeamento discursivo. Em relação aos marcadores conversacionais, especificamente, os de modalidade deôntica, o objetivo desta pesquisa, faremos um detalhamento acerca deles na seção seguinte.

\section{Os marcadores conversacionais de modalidade deôntica}

Segundo Zorraquino e Portolés (1999), os marcadores de modalidade deôntica estão relacionados com as atitudes do falante no que se refere à expressão das suas vontades e afetos, indicando se o falante admite ou não o que é proposto no fragmento do discurso ao qual remete. Dessa forma, ainda que se considerem os marcadores conversacionais de modalidade deôntica como elementos assertivos, eles, na verdade, incidem sobre enunciados diretivos, já que culminam em uma proposta, um oferecimento, uma avaliação, etc., tendo em vista 
que os próprios marcadores em si indicam que o falante interpreta o enunciado ao qual remete como um enunciado dessa índole.

Os marcadores conversacionais de modalidade deôntica, conforme Zorraquino e Portolés (1999, p. 4162), também podem alternar com outros procedimentos expressivos, como por exemplo, os verbos realizativos, tais como acepto (aceito), consiento (consinto), admito (admito), etc., e as construções verbais copulativas, que costumam vir acompanhadas de um predicado ou um complemento circunstancial, cuja básica léxica coincide ou está completamente relacionada com o marcador, tais como está bien ou bien está (está bem), bueno está (está bom), etc. Para exemplificar, temos os seguintes casos: No le han concedido el premio. Bueno/Acepto que no le hayan concedido el premio/Bueno está que no le hayan concedido el premio [Não lhe concederam o prêmio. Bom/Aceito que lhe tenham concedido o prêmio/Está bom que não lhe tenham concedido o prêmio] (ZORRAQUINO; PORTOLÉS, 1999, p. 4162). Ainda segundo os autores, os marcadores conversacionais de modalidade deôntica, em língua espanhola, que se comportam como conectores, reduzem-se ao bueno (bom) e bien (bem), como nos exemplos:

(1) PAULA: Siéntese aquí..., conmigo... /DIONISIO: (Sentándose a su lado) Bueno. (ZORRAQUINO; PORTOLÉS, 1999, p. 4163).

[PAULA: Sente-se aqui..., comigo... / DIONÍSIO: (Sentando-se ao seu lado) Bom].

(2) MELQUÍADES: ¿Queréis que organicemos un concurso de baile por parejas, con premios [...]? / TODOS: (Aplaudiendo) ¡Sí, sí! ;Muy bien, muy bien! (ZORRAQUINO; PORTOLÉS, 1999, p. 4164).

[MELQUÍADES: Vocês querem que organizemos um concurso de baile de casais, com prêmio [...]? / TODOS: (Aplaudindo) Sim, sim! Muito bem, muito bem!].

Em relação aos marcadores conversacionais de modalidade deôntica gramaticalizados em língua espanhola, Zorraquino e Portolés (1999) citam: o vale (ok), de acuerdo (de acordo) e formas equivalentes, alguns advérbios terminados em (-mente), como perfectamente (perfeitamente), cabalmente (cabalmente), definitivamente (definitivamente) e uso de interjeições, como ivenga! (venha!). Para exemplificar, temos os seguintes casos:

(3) A: Aquí te dejo los libros. / B: Vale, vale. (ZORRAQUINO; PORTOLÉS, 1999, p. 4169).

[A: Vou deixar os livros aqui. / B: Ok, ok]. 
(4) A: Federico es muy inteligente. / B: Totalmente de acuerdo. Muy de acuerdo. Casi de acuerdo. (ZORRAQUINO; PORTOLÉS, 1999, p. 4170).

[A: Federico é muito inteligente. / B: Totalmente de acordo. Muito de acordo. Quase de acordo].

(5) - Lo mejor es que tú acudas a las seis de la mañana a casa de Alejo Fernández Flórez. / - Perfectamente - contestó Rico. (ZORRAQUINO; PORTOLÉS, 1999, p. 4170).

[É melhor que você compareça às seis horas da manhã na casa do Alejo Fernández Flórez. / - Perfeitamente - respondeu Rico].

(6) DOÑA SACRAMENTO: [...] Se refiere usted a que no está mi hijo entre nosotros. / DON ELIGIO: Cabalmente. (ZORRAQUINO; PORTOLÉS, 1999, p. 4171).

[DONA SACRAMENTO: [...] Se o senhor se refere ao fato de que o meu filho não está entre nós. / SENHOR ELIGIO: Cabalmente].

(7) ENC: [...] allí comienza, dicen los sicólogos, dicen los siquiatras, ¿no?, que desde allí comienza a formarse la personalidad del individuo. / INF: ...definitivamente, sí... (ZORRAQUINO; PORTOLÉS, 1999, p. 4171).

[ENC: [...] Ali começam, dizem os psicólogos, dizem os sociólogos, dizem os psiquiatras, não? Que a partir dali começa a se formar a personalidade do indivíduo. / INF: ...definitivamente... sim].

(8) - Una pregunta muy personal... / ;Venga! (ZORRAQUINO; PORTOLÉS, 1999, p. 4171).

[- Uma pergunta muito pessoal... / ¡Vai!].

Além dos marcadores conversacionais de modalidade deôntica citados anteriormente, apontados por Zorraquino e Portolés (1999), podemos ainda assinalar outros tipos de marcadores conversacionais, com base em Agüero (2016), Ramírez (2016), Taibo-Cao (2016) e Mafud e Carmona (2018).

Conforme Agüero (2016), os marcadores conversacionais que modulam a negociação (ou de modalidade deôntica) são unidades que expressam as atitudes do falante, relacionadas com a expressão das suas vontades, indicando se o falante confirma, por meio dos marcadores discursivos bueno, está bien, desde luego, cómo no, claro, conforme, etc., ou não confirma, ao empregar os marcadores discursivos ni hablar, en absoluto, de ninguna manera, etc., o que lhe é proposto. Ainda segundo a autora, os marcadores órale (pois bem) e ándale/ándele (está certo) também podem atuar como marcadores de modalidade deôntica, como nos exemplos: 
(9) I: tengo veinticuatro años/ E: órale y ¿a qué te dedicas? (AGÜERO, 2016, p. 30).

[I: Tenho vinte e quatro anos. / E: Pois bem, e em que você trabalha?].

(10) Ándale pues, te presto mi carro. (AGÜERO, 2016, p. 29).

[Ah tá certo, te empresto o meu carro].

Segundo Ramírez (2016), os marcadores conversacionais de modalidade deôntica fazem referência às atitudes que se relacionam com a vontade ou o afeto, indicando, pois, atitudes volitivo-afetivas. Para a autora, a partícula gramaticalizada ojalá (oxalá), seguida da forma verbal no subjuntivo, funciona como uma partícula que expressa volição, manifestando, pois, uma apreciação afetivo-sentimental, de forma que retoma o que foi dito anteriormente como algo desejável, como por exemplo:

(11) Los jesuitas trabajan muy bien y seguramente acabarán las luchas en el Vaticano. Ojalá sea por muchos años y por bien del mundo. (RAMÍREZ, 2016, p. 64).

[Os jesuítas trabalham muito bem e certamente se acabarão as lutas no Vaticano. Oxalá seja assim por muitos anos e para o bem do mundo].

Para Taibo-Cao (2016), os marcadores conversacionais de modalidade deôntica evidenciam uma atitude de aceitação ou de refutação por parte do falante em relação ao que foi dito previamente. De acordo com o autor, o marcador dale (está bom) atua, em determinados contextos específicos, como um marcador de modalidade deôntica, como no exemplo:

(12) E: ¿podemos hacer un corte? / I: dale, dale. (TAIBO-CAO, 2016, p. 88).

[E: Podemos fazer um corte? / I: Tá bom, tá bom].

De acordo com Mafud e Carmona (2018), os marcadores conversacionais de modalidade deôntica referem-se às expressões de vontade e de afeição do falante em relação ao que lhe disposto na interação verbal. Segundo as autoras, os marcadores conversacionais claro (claro) e ya (já) também funcionam como marcadores de modalidade deôntica se inseridos em alguns contextos específicos, como: 
(13) E.: Felicia / iy tú le inculcas esas ideas a tus hijos? // I.: claro / claro / de hecho yo vengo a trabajar como quiera. (MARFUD; CARMONA, 2018, p. 43).

[E: Felícia / e você coloca essas ideias na cabeça dos seus filhos? // I: claro / claro / de fato eu venho trabalhando como queira].

(14) I: Todo eso que aprendí pues me ha servido de mucho / no sé si / yo creo que he hablado de más o // E.: no nono // perfectamente // I.: ya. (MARFUD; CARMONA, 2018, p. 43).

[I: Tudo isso que aprendi, tenho sido muito útil para mim / não sei se / eu acho que eu falei demais ou // E: não, não // perfeitamente // I: já].

Em suma, os marcadores conversacionais de modalidade deôntica são, conforme Torre (2018), aqueles que refletem as atitudes do falante no que diz respeito à expressão de vontades e afetos, indicando se o falante admite ou não o que se infere no fragmento do discurso ao qual remete. Nesse sentido, os marcadores de modalidade deôntica afetam os enunciados diretivos, podendo incidir sobre uma proposta, um oferecimento, uma apreciação, etc., no que tange ao falante em aceitá-las ou recusá-las. Com base nas considerações feitas acerca dos marcadores conversacionais de modalidade deôntica, apresentamos, em forma de resumo, o Quadro 1. Vejamos:

Quadro 1 - Os tipos de marcadores conversacionais de modalidade deôntica

Definição de marcadores conversacionais de modalidade deôntica

São marcadores que refletem as atitudes do falante no que diz respeito à expressão de vontades e afetos, indicando se o falante admite ou não o que se infere do fragmento do discurso ao qual remete.

Tipos de marcadores conversacionais

1- 0 emprego de verbos realizativos (acepto, consiento, admito, etc.);

2- 0 uso de marcadores que confirmam o que é proposto, como bueno, bien, está bien, bien está, bueno está, desde luego, cómo no, claro, conforme, vale, venga, órale, ándale/ándele, dale, ya, etc.;

3- A utilização de marcadores que negam o que é proposto, como ni hablar, en absoluto, de ninguna manera, etc.;

4- $\mathrm{O}$ uso do marcador de acuerdo (e formas equivalentes, como casi de acuerdo, muy de acuerdo, totalmente de acuerdo, etc.);

5- 0 emprego de alguns advérbios terminados em -mente (perfectamente, cabalmente, definitivamente, etc.);

6- A utilização de expressões volitivo-afetivas, como ojalá+subjuntivo.

Fonte: Elaborado pelo autor com base em Zorraquino e Portolés (1999), Agüero (2016), Ramírez (2016), Taibo-Cao (2016), Mafud e Carmona (2018) e Torre (2018). 
Tendo feito as considerações necessárias sobre os marcadores conversacionais de modalidade deôntica, passemos para a metodologia empregada nesta pesquisa na seção seguinte.

\section{Metodologia}

Para o desenvolvimento desta pesquisa, selecionamos seis entrevistas que foram realizadas com o Papa Francisco entre os anos de 2014 e 2017, sendo elas de divulgação online. Reiteramos que as entrevistas foram selecionadas sem que nos pautássemos em questões mais específicas, como a escolha de entrevistas feitas com o Sumo Pontífice que fossem de cunho, estritamente, religioso, político, econômico, social, cultural, etc. As entrevistas foram escolhidas, particularmente, com base na quantidade mínima de 2.000 palavras para que pudéssemos localizar o máximo possível de marcadores conversacionais de modalidade deôntica. Vejamos, no Quadro 2, o detalhamento das entrevistas que foram selecionadas:

Quadro 2 - As entrevistas selecionadas para a composição do corpus

\begin{tabular}{|c|c|c|}
\hline $\begin{array}{l}\text { Título e dada da publicação da } \\
\text { entrevista }\end{array}$ & $\begin{array}{l}\text { Link da entrevista e data de acesso on- } \\
\text { line }\end{array}$ & $\begin{array}{c}\text { Quantida } \\
\text { de de } \\
\text { palavras }\end{array}$ \\
\hline $\begin{array}{l}\text { ENTREVISTA } 01 \text { - El peligro en } \\
\text { tiempos de crisis es buscar un } \\
\text { salvador que nos devuelva la } \\
\text { identidad y nos defienda con } \\
\text { muros. } 21 \text { de janeiro de } 2017 \text {. }\end{array}$ & $\begin{array}{l}<\text { https://elpais.com/internacional/2017 } \\
\text { /01/21/actualidad/1485022162_84672 } \\
\text { 5.html>. Acesso em: } 18 \text { ago. } 2018\end{array}$ & 7.600 \\
\hline $\begin{array}{l}\text { ENTREVISTA } 02 \text { - Entrevista al } \\
\text { Papa Francisco de la revista } \\
\text { holandesa Straatnieuws. } 06 \text { de } \\
\text { novembro de } 2015 .\end{array}$ & $\begin{array}{c}<\text { https://www.aciprensa.com/noticias/t } \\
\text { exto-completo-entrevista-al-papa- } \\
\text { francisco-de-la-revista-callejera- } \\
\text { holandesa-straatnieuws-77696>. Acesso } \\
\text { em: } 18 \text { ago. } 2018\end{array}$ & 2.500 \\
\hline $\begin{array}{l}\text { ENTREVISTA } 03 \text { - Entrevista al } \\
\text { Papa Francisco en el periódico } \\
\text { argentino La Nación. } 04 \text { de } \\
\text { dezembro de } 2014 .\end{array}$ & $\begin{array}{l}\text { <http://es.catholic.net/op/articulos/554 } \\
\text { 06/cat/66/entrevista-al-papa-francisco- } \\
\text { en-el-periodico-argentino-la- } \\
\text { nacion.html\#modal>. Acesso em: } 18 \text { ago. } \\
2018\end{array}$ & 3.400 \\
\hline $\begin{array}{l}\text { ENTREVISTA } 04 \text { - Entrevista del } \\
\text { Papa Francisco a Televisa en } \\
\text { segundo aniversario de su } \\
\text { pontificado. } 13 \text { de março de } \\
2015 .\end{array}$ & $\begin{array}{c}\text { <https://www.aciprensa.com/noticias/n } \\
\text { ueva-entrevista-el-papa-francisco- } \\
\text { explica-como-fue-su-eleccion-hace-dos- } \\
\text { anos-82104>. Acesso em: } 03 \text { nov. } 2018\end{array}$ & 11.100 \\
\hline $\begin{array}{l}\text { ENTREVISTA } 05 \text { - Entrevista al } \\
\text { Papa Francisco en el semanario } \\
\text { católico belga "Tertio" Imagen } \\
\text { referencial. } 07 \text { de dezembro de } \\
2016 .\end{array}$ & $\begin{array}{c}<\text { https://www.aciprensa.com/noticias/t } \\
\text { exto-entrevista-al-papa-francisco-en-el- } \\
\text { semanal-catolico-belga-tertio-72704>. } \\
\text { Acesso em: } 03 \text { nov. } 2018\end{array}$ & 2.800 \\
\hline ENTREVISTA & <https://www.aciprensa.com/noticias/t & 3.700 \\
\hline
\end{tabular}




\begin{tabular}{|l|c|c|}
\hline $\begin{array}{l}\text { entrevista del Papa con TV2000 } \\
\text { sobre el Año de la Misericordia. } 20 \\
\text { de novembro de 2016. }\end{array}$ & $\begin{array}{c}\text { exto-nueva-entrevista-del-papa-con- } \\
\text { tv2000-sobre-el-ano-de-la-misericordia- } \\
90270>\text {. Acesso em: 03 nov. 2018 }\end{array}$ & \\
\hline \multicolumn{2}{|r|}{ Total de palavras } & $\mathbf{3 1 . 1 0 0}$ \\
\hline
\end{tabular}

Fonte: Elaborado pelo autor.

Em relação ao gênero entrevista, Dolz e Schneuwly (2013) afirmam que ele se trata de um gênero jornalístico relacionado ao encontro entre um jornalista (o entrevistador, que representa um determinado grupo editorial) e uma pessoa que se tem o interesse particular de entrevistar (o entrevistado). Conforme os autores, uma entrevista consiste em falar com alguma pessoa expert acerca de um determinado assunto, no intuito de comunicar às informações que se julgam necessárias a terceiros. De acordo com os autores, o entrevistador deve fazer uma triagem das informações que serão veiculadas durante a entrevista, assim como uma reorganização dos elementos que serão inicialmente utilizáveis, para, posteriormente, estruturar uma hierarquização das ideias principais e secundárias.

Dolz e Schneuwly (2013) discorrem também acerca das partes que compõe uma entrevista, a saber: (i) a fase de abertura, em que há o primeiro contato entre o entrevistador e o entrevistado; (ii) a fase de introdução do tema, em que o entrevistador inicia o discurso, sendo, portanto a fase da apresentação e delimitação do assunto; (iii) a apresentação do plano da exposição, em que o entrevistador torna transparente e explícitas para o entrevistado as operações de planejamento da exposição dos temas que serão abordados durante a entrevista; (iv) o desenvolvimento $e$ o encadeamento dos diferentes temas, em que o entrevistador vai guiando a entrevista ao intercalar temas, elaborar perguntas acerca daquilo que vai sendo dito pelo entrevistado, etc.; (v) a fase de recapitulação e síntese, em que o entrevistador retoma os principais temas que norteiam a entrevista, fazendo uma transição entre a exposição em si e sua fase de conclusão; (vi) a conclusão, em que o entrevistador transmite uma mensagem final, permitindo ao entrevistado desencadear algum novo problema ou iniciar um outro debate; e (vii) o encerramento, em que o entrevistador e o entrevistado proferem seus agradecimentos, o que se caracteriza como uma configuração interacional entre eles.

Baseando-se na composição de uma entrevista, é possível que se entreveja que toda entrevista mantém-se no princípio do dialogismo por meio de perguntas e respostas, em que o entrevistador elabora perguntas ao entrevistado que, por sua vez, responde-as. Por isso, acreditamos que essa interação, que vai se construindo durante a entrevista, nesse jogo comunicativo pergunta/resposta, propicie o uso de marcadores conversacionais, principalmente, os de modalidade deôntica, em que o entrevistado (no caso, o Papa Francisco) faz uso deles no seu encadeamento discursivo por meio das respostas que são dadas ao seu entrevistador. Isso é o que veremos, qualitativamente, na seção seguinte, para os marcadores conversacionais de modalidade deôntica. 


\section{Descrição e análise dos marcadores conversacionais deônticos nas entrevistas do Papa Francisco}

Nesta seção, descreveremos e analisaremos, qualitativamente, os marcadores conversacionais deônticos nas entrevistas do Papa Francisco que foram selecionadas para a composição do corpus, dos quais pretendemos explanar, primeiramente, os marcadores de modalidade deôntica que expressam as vontades do falante, para, posteriormente, passarmos para os casos volitivo-afetivos. Por último, faremos uma abordagem dos casos de que são avaliados pelo falante como obrigação, tendo em vista que a modalidade deôntica, conforme Hengeveld e Mackenzie (2008), está relacionada ao que é moral, social e legalmente aceito com base em convenções de normas sociais e regras de conduta.

Passemos, agora, para os casos de manifestação das vontades do falante. Vejamos (1) e (2):

(1) Entrevistador: ¿Cuáles son sus mayores preocupaciones con respecto a la Iglesia y en general con la situación mundial?

Papa Francisco: Con respecto a la Iglesia, yo diría que la Iglesia no deje de ser cercana. $O$ sea, que procure ser continuamente cercana a la gente. (ENTREVISTA 01).

[Entrevistador: Quais são suas maiores preocupações com relação à Igreja e, no geral, com a situação mundial? / Papa Francisco: Com relação à Igreja, eu diria que a Igreja não deixe de estar próxima das pessoas. Ou seja, que procure ser continuamente próxima das pessoas].

(2) Entrevistador: [...] En el Sínodo Usted dio plena libertad para que se dijera lo que cada uno pensaba. Había cardenales que pisaban el acelerador, los otros pisaban el freno, unos decían que Usted quería que se pisara el acelerador ¿Qué espera de este segundo Sínodo?

Papa Francisco: El secretario, me trae los tres temas más votados, me decía el más votado es éste, qué aporte, el aporte de Jesucristo al hombre de hoy. Y bueno, hagamos éste. Así era el título del Sínodo. (ENTREVISTA 04).

[Entrevistador: [...] No Sínodo o Senhor deu plena liberdade para que cada um falasse o que pensava. Havia cardeais que pisavam o acelerador, os outros pisavam o freio, uns diziam que o Senhor queria que se pisasse o acelerador. 0 que espera deste segundo Sínodo? / Papa Francisco: O secretário, trouxe-me os três temas mais votados, me dizia que o mais votado é este, que o pedido, o pedido de Jesus Cristo ao homem de hoje. E bom, façamos isto. Assim era o título do Sínodo].

Em (1), vemos que o Papa Francisco faz uso do marcador conversacional continuamente (continuamente) para manifestar uma vontade sua de que a Igreja esteja, de forma continuada, sempre próxima das pessoas. Constatamos também 
que este marcador discursivo é ancorado por "satélites" que o circundam para "sinalizar" à vontade (volição) do Sumo Pontífice, como as completivas com que empregadas por ele, assim como por aquilo que o entrevistador veicula em sua pergunta, que está relacionado ao afetivo, como "as maiores preocupações do Papa". De acordo com Marques (2001), as "completivas com que" permitem a ocorrência do modo subjuntivo (irrealis), o que semanticamente pode estar relacionado, a depender do contexto em que são empregadas, à manifestação de valores como vontade, desejo e volição, principalmente quando as completivas com que são antecedidas de verbos volitivos, como querer, apetecer, exigir, pedir, preferir, pretender, admitir, recomendar, requerer, rogar, solicitar, sugerir, suplicar, urgir, negar.

Em (2), averiguamos que o Santo Padre utiliza o marcador conversacional bueno (bom) para reafirmar a sua vontade em relação à "realização do Sínodo sobre as famílias", o que é atenuado pelo uso do imperativo afirmativo hagamos (façamos). De acordo com Barros (2017), para as modalizações deônticas ocorre à construção de uma relação entre o falante (que é o sujeito da enunciação) e o ouvinte (o sujeito sobre quem recai a atitude modal), o que desencadeia na realização do evento deôntico. Nesse sentido, o modo imperativo marca, prototipicamente, a modalidade deôntica, sendo instaurada por modalizadores como dever, poder, é necessário, ter+de+infinitivo, ter+que+infinitivo e outras construções modalizadoras deônticas, como ter a obrigação de, estar obrigado a, ter o dever de, etc. Para exemplificar, Barros (2017, p. 85) cita os seguintes exemplos: A Cigarra deve aprender a lição/A Cigarra pode aprender a lição.

Ainda em relação ao caso (2), é notável que a pergunta feita pelo entrevistador contenha duas modalizações volitivas, Usted quería que se pisara el acelerador e ¿Qué espera de este segundo Sínodo?, o que, segundo Hengeveld e Mackenzie (2008), são modalizações que estão relacionadas ao que é (in)desejável (eixo da volição). As modalizações volitivas encontradas podem também funcionar como uma espécie de "satélite" que circunda o marcador conversacional de modalidade deôntica, em que há um deslocamento do querer-desejar (a esperança de que o Sínodo da Família dê os resultados esperados) para o querer-fazer (pretender ser mais cauteloso em relação às mudanças no conceito de família), para, posteriormente, culminar no dever-fazer (a realização do Sínodo da Família). Reiteramos que os autores, em sua tipologia das modalidades, fazem uma distinção entre as modalidades deôntica e volitiva, sendo está relacionada ao eixo da volição, enquanto aquela está relacionada ao eixo da conduta.

Tendo analisado os casos de manifestação das vontades do falante por meio dos marcadores discursivos de modalidade deôntica, vejamos os casos de (3) a (7) que se referem aos casos volitivo-afetivos:

(3) Entrevistador: [...] Hay quienes sostienen que para entenderlo a usted conviene conocer a Pablo VI. Él fue hasta cierto punto el papa incomprendido. ¿ Se siente también un poco así, un Papa incómodo? Papa Francisco: Sí, alguno por ahí no está de acuerdo, y tiene derecho, porque si yo me sintiera mal porque alguien no está de acuerdo habría en mi actitud un germen de dictador. Tienen 
derecho a no estar de acuerdo. Todos tienen derecho a discutir, y ojalá discutiéramos más porque eso nos pule, nos hermana. (ENTREVISTA 01).

[Entrevistador: [...] Há quem diga que para entender o senhor é preciso conhecer a Paulo VI. Ele foi até certo ponto o Papa incompreendido. 0 senhor se sente também um pouco assim, um Papa incômodo? / Papa Francisco: Sim, alguém por aí não está de acordo, e tem o direito, porque se eu me sentisse mal porque alguém não e está de acordo, haveria em minha atitude um gérmen de ditador. Têm direito a não estarem de acordo. Todos têm direito a discutir, e oxalá discutíssemos mais, porque isso é preciso, nos aproxima como irmãos].

(4) Entrevistador: Papa Francisco, Usted envió un correo privado a un amigo de Argentina expresándole su preocupación acerca de la creciente difusión del narcotráfico en su propio país. Y utilizó el término "tratemos de evitar la mexicanización" [...]

Papa Francisco: También ¿no? Así que yo contesté rezo, los acompaño, y ojalá no lleguemos a la mexicanización, técnicamente. (ENTREVISTA 04).

[Entrevistador: Papa Francisco, o senhor enviou um e-mail em particular para um amigo argentino, expressando sua preocupação acerca da crescente difusão do narcotráfico em seu próprio país. E utilizou a expressão "tratemos de evitar a mexicanização" [...] / Papa Francisco: Também, não? Assim que eu respondi com oração, acompanhando-os, e oxalá não cheguemos à "mexicanização", tecnicamente].

Como citado anteriormente, o emprego do marcador conversacional ojalá+subjuntivo (oxalá+subjuntivo), conforme Ramírez (2016), é uma partícula que expressa tanto um desejo do falante quanto uma apreciação afetivosentimental do estado-de-coisas desejado. Em (3), este marcador conversacional remete à vontade do Papa Francisco de que "as pessoas debatam mais sobre aquilo que ele pronuncia, já que não é da sua intenção agir como um ditador", enquanto, em (4), volta-se para a questão da "não mexicanização da sociedade argentina no que tange ao crescimento do narcotráfico". É necessário que pontuemos que o marcador conversacional ojalá+subjuntivo também é circundado por cláusulas que expressam o que é relativo ao estado afetivo-sentimental do Santo Padre, respectivamente, os casos "¿Se siente también un poco así, un Papa incómodo?", "si yo me sintiera mal" e "expresándole su preocupación".

Além da construção volitiva ojalá+subjuntivo, outro tipo de construção volitiva, funcionando como um marcador conversacional de modalidade deôntica, foi encontrado nas entrevistas do Papa Francisco, no caso, a construção que+subjuntivo. Vejamos (5) e (6):

(5) Entrevistador: En sus consistorios, ha creado cardenales de los cinco continentes. ¿Cómo le gustaría que fuese el cónclave que elija a su sucesor? ¿Cree que verá el próximo conclave? 
Papa Francisco: Que sea católico. Un cónclave católico que elija a mi sucesor. (ENTREVISTA 01).

[Entrevistador: Em suas reuniões com os cardeais, o senhor institui cardeais dos cinco continentes. Como o senhor gostaria que fosse o conclave que irá escolher o seu sucessor? / Papa Francisco: Que seja católico. Um conclave católico que escolha o meu sucessor].

(6) Entrevistador: En Cracovia usted ofreció a los jóvenes impulsos preciosos. ¿Cuál sería un mensaje particular para los jóvenes de nuestro país?

Papa Francisco: Que no tengan miedo, que no tengan vergüenza de la fe, que no tengan vergüenza de buscar caminos nuevos. (ENTREVISTA 05).

[Entrevistador: Na Cracóvia, o senhor ofereceu aos jovens impulsos preciosos/Papa Francisco: Que não tenham medo, que não tenham vergonha da sua fé, que não tenham vergonha de buscar novos caminhos].

Em (5) e (6), vemos que o Papa Francisco emprega a construção volitiva que+subjuntivo como um marcador conversacional de modalidade deôntica para manifestar suas vontades e afetos, respectivamente, no que concerne ao fato do "futuro conclave ser católico em sua plenitude" e que a juventude católica da Cracovia não "tenham medo e vergonha de sua fé católica". Para Grande Alija (1996), as ilocuções optativas compostas por meio da construção volitiva que+subjuntivo, obrigatoriamente, só podem vir reintegradas a um elemento de subordinação, em que o emprego do modo subjuntivo reforça o seu caráter volitivo; ou, em alguns casos, essas construções vêm acompanhadas de "verdadeiras fórmulas" ou "frases mais ou menos estereotipadas" para a expressão do desejo. Para Hengeveld e Mackenzie (2008, p. 73), o que caracteriza uma ilocução optativa é o fato de o falante indicar ao seu(s) ouvinte(s) o seu desejo de que a situação evocada pelo conteúdo comunicado possa de alguma forma ocorrer, como no exemplo: Let her be there! [Que ela esteja lá!]. Especificamente, em (5), é possível percebermos que o Santo Padre emprega "completivas com que", o que também atenua o caráter volitivo-afetivo do marcador conversacional de modalidade deôntica.

Salvo as construções ojalá+subjuntivo e que+subjuntivo, segundo Torre (2018), as expressões que remetem a agradecimentos, saudações e despedidas também podem ancorar os marcadores conversacionais de modalidade deôntica ou substituí-los na manifestação das volições-afetivas do falante, como podemos ver em (7):

(7) Entrevistador: Gracias Santidad y felicidades adelantadas...

Papa Francisco: Gracias a ustedes por lo que hacen con la comunicación y la proclamación de la Palabra del Señor [...] (ENTREVISTA 06). 
[Entrevistador: Obrigado Vossa Santidade e felicidades adiantadas.../Papa Francisco: Obrigado a vocês pelo que fazem com a comunicação e a proclamação da Palavra do Senhor].

Em (7), atestamos que o Papa Francisco emprega o marcador conversacional de modalidade deôntica, no caso, a fórmula gracias (obrigado), para expressar uma volição-afetiva em relação aos "trabalhos desenvolvidos pelo grupo religioso de comunicação em proclamar a Palavra do Senhor". Segundo Torre (2018), nos casos em que fórmulas de despedidas, de saudações ou de agradecimentos são usadas como marcadores conversacionais de modalidade deôntica, elas incidem sobre uma interpretação da volição-afetiva do falante como uma "ação" (querer-fazer) dirigida para o ouvinte.

Além dos casos de manifestação das vontades do falante e dos casos volitivoafetivos, haja vista que os marcadores conversacionais de modalidade deôntica refletem as atitudes do falante no que diz respeito à expressão de suas vontades e afetos, acreditamos que os casos relacionados às obrigatoriedades inerentes ao falante, ou com aquilo que ele julga ser, possam também ser marcados, linguisticamente, por meio de marcadores conversacionais próprios, podendo ser ancorados por meio de modalizadores deônticos. Vejamos (8):

(8) Papa Francisco: [...] Yo siento que existe el agotamiento, pero no le tengo miedo. Debo continuar hablando de la verdad y de cómo son las cosas.

Entrevistador: ¿Es su deber?

Papa Francisco: Sí, es mi deber. Lo siento dentro de mí. No es un mandamiento, pero como personas todos tenemos que hacerlo. (ENTREVISTA 02).

[Papa Francisco: [...] Eu sinto que existe o esgotamento, mas não tenho medo disso. Devo continuar falando da verdade e de como são as coisas/Entrevistador: É seu dever? / Papa Francisco: Sim, é meu dever. Sinto isso dentro de mim. Não é um mandamento, mas como as pessoas, todos nós temos que fazê-lo].

Em (8), temos que o advérbio de afirmação Sí (sim) retoma o que é entendido pelo Santo Padre como uma obrigação sua, no que tange ao "dever de continuar falando a verdade e de como as coisas são", sendo esse marcador discursivo ancorado por modalizadores deônticos, como o auxiliar modal deber (dever) e a construção perifrástica tener+que+infinitivo (ter+que+infinitivo). 0 emprego de modalizadores deônticos pelo Papa Francisco atenua o que ele avalia como algo que lhe obrigatório, tendo o advérbio de afirmação Sí um marcador discursivo que confirma essa obrigatoriedade. Nesse sentido, o uso da modalidade deôntica, que, segundo Hengeveld e Mackenzie (2008), refere-se ao que é moralmente, socialmente e legalmente obrigatório, permitido ou proibido em termos de normas e regras de conduta social, funciona como um "satélite" que orbita o marcador conversacional de modalidade deôntica, atribuindo-lhe um valor semântico de obrigação, permissão ou proibição. 
Em (8), a modalização deôntica, Debo continuar hablando de la verdad y de cómo son las cosas, constatamos, ainda conforme os autores, um caso de modalidade deôntica orientada para o Participante, pois averiguamos que há a descrição de uma obrigação, no caso, uma obrigação interna, que recai sobre o falante (instaurada por ele) de se envolver no evento que é designado pelo enunciado. Com relação ao marcador discursivo empregado em (8), este poderia ser também substituído por outros marcadores equivalentes, sem que houvesse prejuízo ao que é manifestado pelo Santo Padre acerca de suas obrigações, tais como claro, de acuerdo, por supuesto, definitivamente, etc. Retomando o caso (8), temos: Entrevistador: ¿Es su deber? Papa Francisco: Sí/claro/de acuerdo/por supuesto/definitivamente, es mi deber. Lo siento dentro de mí. No es un mandamiento, pero como personas todos tenemos que hacerlo.

Reformulando o que é proposto no Quadro 1, apresentamos o Quadro 3 que traz a definição dos marcadores conversacionais de modalidade deôntica e os tipos de marcadores conversacionais que remetem às vontades, aos afetos e às obrigações do falante que foram descritos e analisados nesta pesquisa:

Quadro 3 - Os tipos de marcadores conversacionais de modalidade deôntica

Definição de marcadores conversacionais de modalidade deôntica

São marcadores que refletem as atitudes do falante no que diz respeito à expressão de suas vontades, seus afetos e suas obrigações em relação ao que lhe é proposto.

\section{Tipos de marcadores conversacionais}

1- 0 emprego de verbos realizativos (acepto, consiento, admito, etc.);

2- 0 uso de marcadores que confirmam o que é proposto, como bueno, bien, está bien, bien está, bueno está, desde luego, cómo no, claro, conforme, vale, venga, órale, ándale/ándele, dale, ya, etc.;

3- A utilização de marcadores que negam o que é proposto, como ni hablar, en absoluto, de ninguna manera, etc.;

4- 0 uso do marcador de acuerdo (e formas equivalentes, como casi de acuerdo, muy de acuerdo, totalmente de acuerdo, etc.);

5- 0 emprego de alguns advérbios terminados em -mente (perfectamente, cabalmente, definitivamente, continuamente, etc.);

6- A utilização de expressões volitivo-afetivas, como ojalá+subjuntivo, que+subjuntivo, etc.

7- 0 emprego de marcadores discursivos que remetem a manifestação de obrigações inerentes ao falante, tais como sí, claro, de acuerdo, por supuesto, definitivamente, etc.

Fonte: Elaborado pelo autor.

Dessa forma, temos que os marcadores conversacionais de modalidade deôntica refletem as atitudes do falante no que diz respeito à manifestação das suas vontades, afetos e obrigações, tendo em vista o que lhe é proposto na interação com seu ouvinte. 


\section{Considerações finais}

Os marcadores conversacionais de modalidade deôntica, presentes nas entrevistas do Papa Francisco que foram selecionadas para a composição do corpus desta pesquisa, revelaram que eles exercem tanto as funções específicas de manifestar as atitudes do Santo Padre em relação à expressão de suas vontades e afetos quanto na instauração das obrigações que ele aprecia e avalia como sendo inerentes a sua pessoa em relação ao que lhe é proposto.

Dessa forma, vimos que os marcadores conversacionais de modalidade deôntica são unidades que concatenam o discurso, entendido nesta pesquisa, como o uso efetivo da língua nas interações entre os participantes do ato comunicativo (entrevistador e entrevistado), atuando não apenas como unidades morfossintáticas e semânticas (na manifestação de vontades, afetos e obrigações), mas também como elementos pragmático-discursivos, haja vista que o emprego desses marcadores conversacionais visa a manter o encadeamento discursivo ao longo da entrevista, mediante as perguntas que são feitas pelo entrevistador, que avalia a pessoa que o Papa Francisco representa, e as respostas que são dadas pelo Papa Francisco, ao manifestar suas volições-afetivas e as obrigações que são inerentes a sua pessoa em virtude da responsabilidade que lhe é imposta em razão de sua função religiosa e político-social (Chefe da Igreja Católica e Chefe do Estado do Vaticano).

\section{Referências}

AGÜERO, Alba Nalleli García. Marcadores discursivos indicadores de cortesía de la variedad mexicana: un enfoque pluricéntrico para su enseñanza en E/LE. E-JournALL, EuroAmerican Journal of Applied Linguistics and Languages, Berna, v. III, n. 1, p. 23-42, 2016.

BARROS, S. C. G. Mecanismos linguísticos e relações intersubjetivas na produção de textos: atividades enunciativas na prática de ensino. 2017. 164 f. Tese (Doutorado em Linguística) Universidade Federal de São Carlos, São Carlos, 2017.

CARBONERO, Pedro; MARRERO, Juan Santana. Marcadores del discurso, variación dialectal y variación social. In: LAMAS, Oscar Loureda; VILLA, Esperanza Acín. Los estudios sobre marcadores del discurso en español. Madri: Arco Libros, 2010. p. 497-522.

DOLZ, Joaquim; SCHNEUWLY, Bernard. O oral como texto: como construir um objeto de ensino. In: ROJO, Roxanne; CORDEIRO, Glaís Sales. Gêneros orais e escritos na escola. São Paulo: Mercado de Letras, 2013. p. 149-188.

GRANDE ALIJA, F. J. Las modalidades de la enunciación. 1996. 1129 f. Tese (Doutorado em Filologia) - Universidade de León, Castela e Leão, 1996. 
HENGEVELD, Kees; MACKENZIE, John Lachlan. Functional Discourse Grammar: a typologically based theory of language structure. Oxford: Oxford Linguistics, 2008.

MAFUD, Ana María González; CARMONA, Marialys Perdomo. Aproximación al estudio de los marcadores discursivos en muestras de habla culta de La Habana. Revista de la Universidad de La Habana, Havana, n. 285, p. 25- 49, 2018.

MARQUES, M. L. D. L. O Modo conjuntivo e a expressão de tempo em frases completivas. 2001. 186 f. Dissertação (Mestrado em Linguística) - Universidade do Porto, Porto, 2001.

RAMÍREZ, Sara Quintero. Marcadores discursivos en el blog de José Ramón Fernández. Revista de Lingüística y Literatura, Guadalajara, n. 70, p. 47-69, 2016.

TAIBO-CAO, L. M. Los marcadores del discurso en el habla culta de Montevideo: análisis del corpus PRESEEA. 2016. 148 f. Dissertação (Mestrado em Filologia) - Universidade Nacional de Educação a Distância, Montevidéu, 2016.

TORRE, A. M. T. De la teoría a la práctica: la enseñanza de los marcadores conversacionales de ELE. 2018. 513 f. Tese (Doutorado em Filologia) - Escuela Internacional de Doctorado, Madri, 2018.

ZORRAQUINO, María Antonia Martín; PORTOLÉS, José Lázaro. Los marcadores del discurso. In: BOSQUE, Ignacio; DEMONTE, Violeta. Gramática descriptiva de la lengua española. Madri: Espasa Calpe, 1999. p. 4051-4213.

\section{Para citar este artigo}

OLIVEIRA, André Silva. Os marcadores conversacionais de modalidade deôntica nas entrevistas do Papa Francisco. Miguilim - Revista Eletrônica do Netlli, Crato, v. 8, n. 1, p. 04-23, jan.-abr. 2019.

\section{0 autor}

André Silva Oliveira é mestre em Linguística e doutorando em Linguística pelo Programa de Pós-Graduação em Linguística da Universidade Federal do Ceará (PPGL/UFC).

Apoio/financiamento: Coordenação de Aperfeiçoamento de Pessoal de Nível Superior - Capes. 